\title{
Ideias-força evidenciadas no discurso organizacional sobre sustentabilidade
}

Strength-ideas evidenced in the organizational discourse on sustainability

Ideas-fuerza evidenciadas en el discurso organizacional sobre sustentabilidad

\section{Márcio Simeone Henriques}

- Doutor em Comunicação Social pela Universidade Federal de Minas Gerais (UFMG)

- Graduado em Relações Públicas

- Professor do Departamento de Comunicação Social e do Programa de PósGraduação em Comunicação Social da UFMG

- Participante do grupo de pesquisa "Comunicação no contexto organizacional: aspectos teórico-conceituais" (PUC-Minas/CNPq)

- E-mail: simeone@ufmg.br

\section{Lidiane Ferreira Sant'Ana}

- Mestre em Comunicação Social - Interações Midiáticas pela Pontifícia Universidade Católica de Minas Gerais (PUC-Minas)

- Especialização em Jornalismo: práticas contemporâneas pela PUC-Minas

- Graduada em Relações Públicas

- Membro dos grupos de pesquisa "Comunicação no contexto organizacional: aspectos teóricos e conceituais" (PUC-Minas/CNPq) e "Campo comunicacional e suas interfaces" (PUC-Minas/Fapemig)

- E-mail: lidianefsantana@yahoo.com.br 


\title{
Resumo
}

Sob a ótica da comunicação organizacional, este artigo aborda as estratégias discursivas que as empresas utilizam para conciliar seus negócios e interesses econômicos com as pressões legais e sociais por responsabilidade ambiental. Para entender o lugar de fala que elas assumem, é analisado empiricamente o discurso organizacional sobre a sustentabilidade de três grandes empresas que atuam no Brasil, por meio de três ideias-força: responsabilidade pelo impacto ambiental gerado pela empresa; adoção de práticas mitigadoras de danos ambientais; e estímulo à adoção de atitudes sustentáveis por parte dos demais atores sociais.

PALAVRAS-CHAVE: SUSTENTABILIDADE • ORGANIZAÇÕES • DISCURSO

\begin{abstract}
From the perspective of organizational communication, this article focuses on the discursive strategies that companies use to reconcile their business and economic interests with the legal and social pressures for environmental responsibility. To understand the place of speech that they assume, an empirical study is conducted in order to examine the organizational discourse on the sustainability of three large companies that operate in Brazil, by means of three strength-ideas: responsibility for environmental impact generated by the company, adoption of practices for mitigating environmental damage and the incentive for adopting sustainable attitudes by other social actors.
\end{abstract}

KEYWORDS: SUSTAINABILITY • ORGANIZATIONS • DISCOURSE

\section{Resumen}

Desde el punto de vista de la comunicación organizacional, este artículo aborda las estrategias discursivas que las empresas utilizan para conciliar sus intereses económicos y de negocios con las presiones legales y sociales por responsabilidad ambiental. Para comprender el lugar desde donde hablan, se examina empíricamente el discurso organizacional sobre la sustentabilidad de tres grandes empresas que actúan en el Brasil, por medio de tres ideas-fuerza: responsabilidad del impacto ambiental generado por la empresa; adopción de prácticas mitigadoras de daños al medio ambiente; y el incentivo para adoptar actitudes sustentables por parte de los demás actores sociales.

PALABRAS CLAVES: SUSTENTABILIDAD • ORGANIZACIONES • DISCURSO 
O discurso das organizações em torno da sustentabilidade é motivado tanto por questões legais quanto por demandas de caráter mais geral da sociedade. Atentos ao uso indiscriminado de recursos e ao seu impacto sobre as condições naturais, os consumidores tendem a optar por produtos e serviços de empresas que adotem posturas ambientalmente responsáveis. Além disso, mesmo quem não consome diretamente tais produtos não se priva de denunciar práticas prejudiciais ao meio ambiente, diante da preocupação mais disseminada com a finitude dos recursos da natureza. Ao adotarem o discurso da sustentabilidade, as empresas estão investindo na sua permanência em curto e médio prazos no mercado. Fazer parte de uma "lista suja" prejudica a imagem e pode dificultar os negócios e a obtenção de certificações de boas práticas, essenciais para manter e expandir transações.

Em um cenário no qual as questões ambientais (em sentido estrito) e sociopolíticas (em sentido amplo) se inscrevem cotidianamente na agenda pública, declarar a adoção de princípios de sustentabilidade tornou-se estratégia basilar no meio empresarial. Diante disso, a pesquisa ${ }^{1}$ que deu origem a este artigo propõe investigar as questões que tangem as estratégias comunicacionais no campo da sustentabilidade. Por despertarem a manifestação discursiva de grupos sociais que monitoram sua atuação, as empresas Braskem, Fibria e Monsanto, foram escolhidas como objetos do estudo.

Para o propósito da pesquisa, de analisar a resposta social ${ }^{2}$ registrada nas redes sociais digitais quanto ao discurso dessas empresas, foi preciso marcar o lugar de fala de cada uma delas. Assim, investigaram-se preliminarmente os discursos por elas elaborados e postos em circulação, a fim de identificar as marcas discursivas que denotam suas estratégias para adequar-se às exigências e demonstrar interesse e comprometimento com a causa ambiental. A fase de investigação exploratória e a revisão de literatura sobre o tema da sustentabilidade revelaram a presença de alguns sentidos predominantes nesses discursos. Assim, os esforços se voltaram para a análise dos traços discursivos que evidenciassem a presença de algumas ideias-força nos textos produzidos pelas empresas. A seguir são apresentados, exemplificados e analisados tais traços ${ }^{3}$.

\section{A SUSTENTABILIDADE NA PRODUÇÃO DISCURSIVA DAS ORGANIZAÇÕES}

O discurso estabelece uma reflexividade com a prática e constitui um modo não só de representação, como também de ação. Se, por um lado, o discurso reproduz a sociedade, à medida

\footnotetext{
${ }^{1}$ A pesquisa intitulada "Mecanismos de resposta social em redes virtuais: um estudo sobre a interação entre as organizações e a sociedade, articulada pelo discurso da sustentabilidade" é realizada pelo grupo "Comunicação no contexto organizacional: aspectos teórico-conceituais", com financiamento da Fapemig. O estudo é feito por pesquisadores da PUC-MG e da UFMG. 2 Tomamos aqui o termo "resposta social" com base no conceito de José Luiz Braga (2006, p. 22): "atividades de resposta produtiva e direcionadora da sociedade em interação com os produtos midiáticos". No trabalho em questão, este conceito é adaptado para os estudos de comunicação no contexto das organizações. Consideram-se, assim, as respostas referentes ao discurso organizacional.

${ }^{3}$ Registramos nosso especial agradecimento a Luiz Felipe da Mota, estagiário da pesquisa, pelo apoio nesta fase do estudo empírico.
} 
que é moldado pela estrutura e pelo contexto social dos quais emerge, por outro ele também a transforma, ao contribuir para a construção de identidades, relações, conhecimentos e crenças (Fairclough, 2001). As organizações se engajam em uma intensa produção discursiva, em atenção às questões públicas correntes e, simultaneamente, desenham os contornos dessas questões, por meio da produção, da circulação e da resposta social aos seus discursos. Esse conjunto de discursos recorre cada vez mais à temática da sustentabilidade. A questão emerge de um amplo movimento no qual vários discursos são organizados em correntes de sentido em termos do comprometimento dos recursos naturais e também das implicações econômicas e sociais dos empreendimentos.

Conforme ressalta Fairclough (2001), o sentido não é algo unívoco, sobretudo quando o discurso é produzido por falantes diversos. Embora não possamos desconsiderar a ambivalência e abertura dos textos a múltiplas interpretações, é possível identificar traços hegemônicos no discurso das organizações em torno da sustentabilidade.

Um primeiro aspecto de similaridade é extrapolar as questões ambientais para abarcar as dimensões sociais, administrativas e culturais. Essa perspectiva expandida permite usos variados, adequados aos interesses e pontos de vista de quem elabora o discurso. Assim, o termo sustentável torna-se um adjetivo aplicado a empresas, processos, produtos, departamentos e práticas de gestão e marketing. A institucionalização da sustentabilidade faz dela uma questão estratégica para a gestão empresarial, diretamente vinculada ao próprio negócio e à eficiência econômica da empresa.

Essa perspectiva é disseminada para outros campos sociais. A construção discursiva da sustentabilidade tende a extrapolar os limites das empresas não só como forma de divulgar suas práticas ditas ambientalmente corretas, mas também para motivar a adoção de atitudes sustentáveis, condizentes com a ótica da empresa, pelos demais membros da cadeia de produção e consumo e mesmo por toda a sociedade. Uma prática social alinhada à prática da empresa é proposta discursivamente por meio de verbos como reduzir, reutilizar e reciclar.

Incorporado à lógica do mercado, o termo sustentabilidade ganha também urgência, sendo associado a questões civilizatórias. De modo geral, um discurso mais amplo sobre sustentabilidade remete, fundamentalmente, à ideia de sociedades postas em risco - não uma nação ou outra, mas, sob uma visão sistêmica e global, riscos para toda a civilização (Brown, 2009). A ideia de uma mobilização para "salvar o planeta" implica uma consciência global desses riscos e, mais ainda, alguma tomada de atitude para mitigá-los e, eventualmente, revertê-los.

Portanto, as questões ligadas aos danos ao meio ambiente e às formas de reparação desses danos figuram, de certa forma, em uma base comum aos textos sobre sustentabilidade. Contudo, na busca por nuances mais específicas dessa construção discursiva, três ideias-força emergem de nossa investigação: 
1) O apelo à responsabilidade - Deriva da ideia de que a organização deve ser responsável pelo impacto ambiental e social que causa. Este enquadramento não é novo, já que as organizações têm procurado, há muitas décadas, posicionar-se em relação às cobranças dos públicos quanto às suas responsabilidades, o que constituiu, pouco a pouco, uma espécie de "doutrina"da responsabilidade social. Na prática atual, as avaliações técnicas que buscam mensurar esses impactos tendem a gerar um tipo de "balanço". Sob a forma de partidas dobradas são contabilizados os ativos e os passivos, de tal forma que se busque atingir um equilíbrio. Imprime-se aos textos organizacionais correntes a noção de passivo ambiental ou social, que, uma vez diagnosticado, deve requerer ações concretas por parte da organização. Além disso, a visibilidade dessas ações deve servir como resposta - uma prestação de contas à sociedade.

2) O apelo às boas práticas - Ao assumir suas responsabilidades, a organização é premida a adotar práticas "corretas". No caso dos impactos ambientais, a sinalização das boas práticas se dá por meio da tecnologia, dos conhecimentos das técnicas mais eficientes para obter menor dispêndio de energia, usar fontes energéticas alternativas, gerar menos resíduos, bem como melhores formas de descarte e de aproveitamento (tanto no processo de produção quanto no ciclo dos produtos), efetuar controle de efluentes e da geração de ruídos, etc. Em relação aos impactos sociais, as boas práticas são orientadas por um conjunto de crenças e valores que se delineiam conforme os públicos vão entendendo as questões relativas ao bem-viver, sua concepção de trabalho e emprego, sua percepção sobre as vantagens e desvantagens econômicas e - condizente com os textos sobre sustentabilidade - a percepção dos riscos para a coletividade. O conjunto de discursos, enfeixados numa espécie de corrente hegemônica de sentidos, forma um entendimento mais ou menos comum do que são essas boas práticas, como a necessidade de realizar, nas comunidades nas quais atuam, projetos sociais que extrapolem um viés assistencialista (geração de renda, desenvolvimento educacional e cultural). Nessa vertente, a ideia de sustentabilidade está atrelada a uma noção de autonomia, ou seja, atuação social sustentável é aquela que não cria laços de dependência da comunidade com a empresa, podendo, em algum momento, prescindir da sua iniciativa, do seu estímulo e da sua contribuição.

3) O apelo a atitudes sustentáveis - A ideia de sustentabilidade não coloca necessariamente em jogo a generalidade do modelo social e econômico, nem se refere a um questionamento sobre a estrutura do modo de produção vigente, mas busca enquadrá-lo como um sistema benéfico ou mesmo essencial a todos, cujos impactos devem ser assumidos de forma a estabelecer corresponsabilidades (se cada um fizer a sua parte é possível diminuir ou eliminar os riscos). Não busca alterar o volume do que se consome, mas a forma como se consome. Assim, existe um apelo a "atitudes sustentáveis", que são propostas e estimuladas interna e externamente (usar produtos e embalagens de material reciclável, descartar corretamente os resíduos, etc.).

Essas três ideias-força (responsabilidade ambiental e social, adoção de práticas corretas e incentivo a atitudes sustentáveis) são, com frequência, encontradas nos textos por meio dos quais 
as organizações contemporâneas buscam posicionar-se publicamente, enquadrando-se como sustentáveis. Assim, buscamos identificar a presença e analisar os traços dessas três ideias-força, nos discursos sobre sustentabilidade produzidos pelas empresas Monsanto, Fibria e Braskem.

\section{ANÁLISE DO DISCURSO SOBRE SUSTENTABILIDADE}

Sem desconsiderar a existência e importância estratégica das diversas formas não verbais de discurso, foram selecionados para análise textos publicamente acessíveis na internet: apresentação institucional, política de sustentabilidade e de responsabilidade social/ambiental, relatórios anuais e zs institucionais.

\section{Monsanto: a bioteconologia como solução sustentável}

"Agricultura sustentável. É a isso que a Monsanto se dedica". Com essas palavras, a multinacional produtora de biotecnologia agrícola, que comercializa herbicidas e sementes transgênicas, conclui seu vídeo institucional ${ }^{4}$, associando a sustentabilidade à própria definição de seu negócio. O relatório anual de responsabilidade social e sustentabilidade não é disponibilizado no site brasileiro, mas no site internacional, com conteúdo em inglês. No site da filial brasileira, no link "Publicações", há um documento intitulado "Monsanto na Rio + 20". Esse documento sintetiza a perspectiva da empresa sobre o tema:

Os ganhos na produção de sementes geneticamente modificadas também são ambientais. (...) Nos próximos dez anos, os transgênicos irão proporcionar uma diminuição de 146,4 mil toneladas de ingredientes ativos de agroquímicos. Com menos aplicações, haverá menos consumo de água e menor necessidade de entrada de máquinas nas lavouras, consumindo menos combustível e emitindo menos gases causadores do efeito estufa ${ }^{5}$.

Enfatizando que o aumento da população mundial é inversamente proporcional às áreas e aos recursos naturais disponíveis para o cultivo de alimentos, a empresa aponta a inovação agrícola como solução para a fome no mundo, o que atrela a questão da sustentabilidade diretamente ao seu próprio negócio. Agricultura sustentável é definida pela empresa como atender às demandas de uma população em crescimento acelerado. O discurso destaca, sobretudo, o emprego da biotecnologia como solução. Nessa perspectiva, sustentabilidade significa produzir alimentos em quantidade suficiente, suprir necessidades básicas imediatas. Ao sustentar a ideia de que a sociedade global está posta em risco, a Monsanto assume uma posição central como aquela que pode reverter a situação.

\footnotetext{
${ }^{4}$ Disponível em: <http://www.youtube.com/user/monsantobrasil?gl=BR\&hl=pt>. Acesso em: 20/06/ 2012

${ }^{5}$ Disponível em: <http://www.monsanto.com.br/institucional/publicacoes/monsanto_rio_20/pdf/monsanto_rio_20.pdf>.

Acesso em: 16 /06/2012.
} 
A primeira ideia-força é abordada de forma bastante esparsa no discurso da Monsanto. Não obstante a tendência de construir o discurso sobre responsabilidade socioambiental a partir dos impactos que a empresa gera, ela não admite claramente ser um agente cujos processo produtivo ou produtos produzam impactos significativos. O discurso oficial a destaca na posição de "pioneira no desenvolvimento de tecnologias que auxiliam no aumento da produção de alimentos e na preservação do meio ambiente", ou seja, tende a enfatizar a importância e o impacto positivo de seus produtos no meio ambiente.

A empresa recorre de modo expressivo à segunda ideia-força, pautando seu discurso de boas práticas na eficiência dos processos e produtos agroquímicos. Aqui também coloca a questão em termos dos benefícios dos produtos, focando estritamente nos objetivos de seus negócios. Segundo o Programa de Desenvolvimento Sustentável da Monsanto, ação sustentável é oferecer aos produtores agrícolas a possibilidade de "produzir mais, com menos". O documento "Monsanto na Rio + 20", além de expor um compromisso geral de "produzir mais, conservar mais e melhorar vidas" e de listar metas que a empresa considera importantes para a proteção à biodiversidade, por meio do desenvolvimento tecnológico de seus produtos, menciona mais especificamente práticas ambientalmente corretas no processo produtivo, exigidas por lei. São citados os cuidados com os resíduos gerados em suas unidades de pesquisa e produção, com os efluentes do entorno e a promoção de reciclagem das embalagens de seus produtos.

Como já apontamos, ao discorrerem sobre sustentabilidade, as empresas tendem a apresentar uma sociedade posta em risco. A Monsanto segue essa tendência ao propor conscientizar os funcionários, a comunidade e terceiros acerca da questão da sustentabilidade: "Todos os setores da sociedade devem se comprometer com a preservação ambiental e, ainda, responder às necessidades da população global, que deve chegar a 9 bilhões de pessoas até 2050". O posicionamento desses outros agentes como corresponsáveis pela sustentabilidade demonstra o uso da terceira ideia-força.

Às ações voltadas para os funcionários e fornecedores, a Monsanto soma medidas educativas para os consumidores. Isso é evidenciado no programa de Desenvolvimento Sustentável da Monsanto. Ele é apoiado em três pilares, por meio dos quais a empresa se prontifica não só a produzir mais e utilizar menos recursos materiais e naturais, mas também a "compartilhar experiências com produtores, para ampliar o seu acesso a modernas tecnologias agrícolas, especialmente em países pobres e em desenvolvimento"6. Conforme esse discurso, se o agricultor abandonar os modos tradicionais de cultivo e lançar mão dos benefícios da biotecnologia, estará poupando recursos naturais, produzindo mais e contribuindo para acabar com a fome no mundo. Portanto, adotar as técnicas e produtos preconizados pela empresa é a contribuição que ele deve dar ao meio ambiente, reforçando mais uma vez o foco de sustentabilidade que é dado ao seu próprio negócio. 


\section{Fibria: sustentabilidade pautada no relacionamento comunitário}

A Fibria, empresa brasileira produtora e exportadora de celulose, aponta o aumento do consumo do produto como um indicador de desenvolvimento socioeconômico. O discurso, em princípio contraditório com as amplas ações que propõem redução do uso e reutilização do papel, evidencia a estreita relação que a empresa procura estabelecer entre a sustentabilidade e a manutenção do próprio negócio: "A Fibria trabalha para garantir que a crescente demanda global por papel possa ser atendida de forma sustentável", declara e empresa no item "Sustentabilidade", do seu site oficial na internet. Ao desvincular a redução do consumo da ideia de sustentabilidade, a Fibria define no mesmo item o que entende por atitude sustentável com a seguinte frase: "Nesse contexto, a empresa busca contribuir para uma sociedade sustentável, fornecendo com eficiência econômica e responsabilidade social e ambiental a matéria-prima preferida para a fabricação de tipos muito usados de papel: a celulose de eucalipto"7.

O site da Fibria possui um glossário. Nele, sustentabilidade é definida de forma a frisar a importância do crescimento econômico e do atendimento às "necessidades e aspirações humanas",

conceito surgido na década de 1980, com a expressão "desenvolvimento sustentável", que significa ser capaz de satisfazer às próprias necessidades sem reduzir as oportunidades das gerações futuras (Relatório Brundtland, 1987). A sustentabilidade é formada por três pilares: ambiental, social e econômico. Isso significa que, para que uma atividade seja sustentável, ela deve promover crescimento econômico e, ao mesmo tempo, respeitar o meio ambiente e satisfazer as necessidades e aspirações humanas ${ }^{8}$.

A Fibria também expressa a ideia-força relacionada à autorresponsabilidade ao abordar a engenharia genética. No link sobre tecnologia, ela justifica sua aplicabilidade e afirma observar a legislação vigente, procurando eliminar riscos decorrentes dessa tecnologia:

A Fibria acredita que a engenharia genética de espécies florestais trará benefícios à sociedade. A empresa fundamenta suas decisões sobre a pesquisa com eucalipto geneticamente modificado na legislação vigente, conhecimentos científicos e demandas de seus stakeholders, por meio da contínua avaliação dos impactos e ganhos econômicos, ambientais e sociais decorrentes da aplicação desta tecnologia, e do cumprimento de todos os procedimentos técnico-científicos necessários à eliminação dos potenciais riscos associados $^{9}$.

Outra vertente que corrobora a presença da primeira ideia-força é a menção clara à "licença social para operar". Ela se dá associada aos princípios que norteiam a conquista de apoio da comunidade, enumerados e detalhados em seu site como importantes para "conquistar apoio para as operações". Para "longo prazo", especificamente para o ano 2025, ela definiu 23 metas em nove objetivos, sendo o primeiro deles relativo às comunidades, em uma clara intenção de

6 Disponível em: <http://www.monsanto.com.br/monsanto/brasil/ newsletter/geral/01_2010 Janeiro/noticiasmonsanto. asp>. Acesso em: 10/06/2012.

${ }^{7}$ Disponível em: <http://www.fibria.com.br/web/pt/institucional/sustentabilidade.htm>. Acesso em: 02/06/2012

${ }^{8}$ Disponível em: <http://www.fibria.com.br/web/pt/midia/glossario.htm>. Acesso em: 02/06/2012.. 
mostrar-se atenta aos impactos que causa à vizinhança da empresa. O diálogo com a comunidade e parcerias com outras empresas e instituições em iniciativas voltadas para a conservação do meio ambiente são destacados também no Relatório de Sustentabilidade de 2011 como alguns dos maiores avanços da Fibria: "Conseguimos estreitar os laços com os atores sociais de todas as regiões onde estamos presentes, seja com programas de engajamento, encontros comunitários, diálogos ou visitas regulares às comunidades vizinhas"10.

Se o crescente consumo de papel não é considerado pela empresa como questão crítica para a sustentabilidade, a racionalização no uso da matéria-prima e a renovação das fontes das quais ela é extraída é apontada como seu principal compromisso na adoção de práticas ambientalmente corretas. Assim, a meta civilizatória passa por uma medida que, segundo e empresa, é tendência global: tornar os processos mais eficientes a fim de minimizar a geração de poluentes diretamente na fonte de emissão. Na introdução ao seu Programa de Educação Ambiental, afirma: "É desta forma que a Fibria procura trabalhar, investindo em equipamentos, tecnologias limpas de última geração e em processos ecoeficientes para a produção de celulose e papel"11.

A tecnologia é fundamental para ancorar os argumentos quanto à segunda ideia-força. Além de associada às "novas aplicações para a celulose e investigação de outros tipos de produtos oriundos dos nossos processos"12, também aparece como elemento fundamental para a adoção de boas práticas produtivas: "A cada ano diversos projetos de pesquisa são conduzidos a fim de aprimorar seus processos e os seus resultados, sempre em sintonia com a conservação ambiental", reitera na mesma página. Na sequencia do texto, a Fibria afirma investir em processos que "permitam aumento de rendimentos das matérias-primas utilizadas e redução dos custos operacionais". Nesse sentido, a sustentabilidade estaria diretamente ligada aos processos de gestão e à manutenção da saúde financeira da empresa. No Relatório de Sustentabilidade de 2011, a presidência da Fibria destaca o plantio de árvores geneticamente modificadas, ao mesmo tempo em que enumera as ações de redução de custos e garantia da excelência operacional, com foco na missão da empresa de "desenvolver o negócio florestal como fonte renovável e sustentável de vida"13.

A ligação direta entre sustentabilidade e relações com a comunidade explicita o uso da terceira ideia-força no discurso da Fibria, relativo à adesão de outros atores a atitudes sustentáveis. Como já apontamos, a empresa destaca o estreitamento de laços com a comunidade como uma de suas maiores conquistas recentes, mas além disso ressalta a necessidade de adesão do público à ideia de preservação. Dentre as práticas relacionadas no link "Ambiente", do site da

\footnotetext{
${ }_{9}$ Disponível em: <http://www.fibria.com.br/web/pt/institucional/tecnologia.htm>. Acesso em: 02/06/2012.

10 Disponível em: <http://www.fibria.com.br/rs2011/Fibria_Relatorio_de_Sustentabilidade_2011.pdf> . Acessado em: 02/06/2012.

${ }^{11}$ Disponível em: <http://www.fibria.com.br/web/pt/ambiente/programas.htm>. Acesso em: 02/06/2012..

${ }_{12}$ Disponível em: <http://www.fibria.com.br/web/pt/institucional/tecnologia.htm> Acesso em: 10/06/2012.
} 
empresa, mais uma vez é destacada a ideia de sustentabilidade como fruto de ações coletivas. A questão é trabalhada pela Fibria em seu Programa de Educação Ambiental, desenvolvido em núcleos mantidos em quatro comunidades nas quais atua, apelando a um compartilhamento de responsabilidades: "Trabalhando de forma integrada e participativa com a comunidade conseguiremos cada vez mais encontrar soluções em melhoria do meio ambiente e qualidade de vida da comunidade em geral" 14 .

\title{
Cadeia produtiva sustentável: a Braskem dividindo a responsabilidade
}

Assim como as duas empresas citadas, a Braskem associa sustentabilidade estreitamente ao seu negócio. E é bem explícita ao fazer essa correlação: "Na visão da Braskem, os dois aspectos - negócios e sustentabilidade - estão intrinsecamente relacionados, uma vez que o mercado já valoriza, e tenderá a valorizar ainda mais, no futuro, as empresas inovadoras, éticas e comprometidas com o desenvolvimento sustentável"15.

A frase "na Braskem, a busca da sustentabilidade é o que move todas as novas formas de pensar e fazer os plásticos" introduz o vídeo "Química sustentável", destacado no topo da homepage da empresa. O diretor de desenvolvimento sustentável é quem explica como isso é feito:

\begin{abstract}
A Braskem definiu três aspectos relevantes para ampliar a sua contribuição para a sustentabilidade. O primeiro é ter processos e recursos cada vez mais sustentáveis, produzindo cada vem menos impacto no meio ambiente. O segundo é ter um portfólio de produtos cada vez mais sustentáveis, produtos de origem renovável (...). E, por fim, entregar soluções para a sociedade cada vez mais sustentáveis ${ }^{16}$.
\end{abstract}

Com relação à primeira ideia-força, a Braskem admite responsabilidade sobre seus impactos ao afirmar que trabalha para reduzir a emissão de carbono. Conforme o glossário da empresa ${ }^{17}$, promover química sustentável é ofertar produtos considerando seus "impactos econômicos, sociais e ambientais e a sua forma de produção, potencializando os positivos e controlando/ minimizando eventuais impactos negativos".

Nessa mesma linha, no link intitulado "Produtos verdes", a empresa afirma: "Oferecer produtos cada vez mais sustentáveis é um dos pilares de atuação da Braskem para servir melhor aos clientes e à sociedade"18. Por esse motivo intensifica suas pesquisas e se compromete a apresentar inovações para clientes de todo o mundo.

\footnotetext{
${ }^{13}$ Disponível em:<http://www.fibria.com.br/rs2011/pt/> . Acesso em: 02/06/2012.

${ }^{14}$ Disponível em: <http://www.fibria.com.br/web/pt/ambiente/programas.htm> . Acesso em: 02/06/2012.

${ }^{15}$ Disponível em: <http://www3.braskem.com.br/upload/rao/2010/pt/negocios-e-desenvolvimento-sustentavel.html>. Acesso em: 08/06/2012.

16 Disponível em: <http://www3.braskem.com.br/upload/rao/2010/pt/quimica-sustentavel-ou-verde.html>. Acesso em: $08 / 06 / 2012$.
} 
A questão de responsabillidade que mais evidencia a primeira ideia-força é a poluição do ar. O "Manifesto Braskem de mudanças climáticas"19 enfatiza os danos causados aos humanos pelos gases de efeito estufa e conclama todos os setores da sociedade a buscarem "soluções para reverter esse cenário e, sobretudo, tomar atitudes eficazes para assegurar a preservação e o futuro da vida". O compromisso da produtora de resinas plásticas com uma questão que coloca em risco toda a sociedade é exposto nos seguintes termos:

Como um dos principais players globais do setor químico, a Braskem vem trabalhando intensamente para se tornar um exemplo de empresa com uma estratégia comprometida com a economia de baixo carbono (com baixa emissão de gases de efeito estufa). Além disso, sua busca é constante por soluções que representem impactos reais e relevantes para a redução da intensidade de emissões de carbono por produto e por meio de soluções inovadoras ${ }^{20}$.

A Braskem utiliza o Relatório de Sustentabilidade de 2010 para reafirmar os desafios apresentados no relatório do ano anterior. Ao listar suas metas a empresa torna clara sua percepção sobre os impactos que gera: periculosidade de produtos químicos; emissão de gases de efeito estufa; intensidade de consumo de água nos processos produtivos; uso de matérias-primas não renováveis (óleo e gás); destino dos resíduos plásticos no pós-consumo; e fortalecimento da relação com os públicos. A tais questões a Braskem acrescenta a "economia verde", definida como a "economia que resulta na melhoria do bem-estar humano e na equidade social, enquanto reduz significativamente os riscos sociais e ambientais" ou, ainda, "economia de baixo carbono, com eficiente uso de recursos e socialmente inclusiva"21.

O discurso das boas práticas, conforme prevê a segunda ideia-força, é utilizado amplamente pela Braskem, destacando que ela está atenta a toda a cadeia produtiva, desde as práticas de seus fornecedores, a instalação e desativação de unidades fabris, até a reciclagem no pós-consumo. A Braskem é audaciosa ao expor suas metas de sustentabilidade para 2020: "Ser a líder mundial da química sustentável, inovando para melhor servir às pessoas"22. A isso se somariam outras práticas: utilizar melhor os recursos, encontrar novas matérias-primas, gerar menos resíduos, reutilizar e reciclar ao máximo.

Um dos macro-objetivos da empresa se refere às pessoas e, com foco nelas, a Braskem utiliza a terceira ideia-força. São adotadas ações de desenvolvimento de competências para os funcionários e de relacionamento com as comunidades do entorno de suas unidades, além da implantação do Sistema de Excelência em Segurança, Saúde e Meio Ambiente. As metas incluem a redução das taxas de acidentes e de novas doenças ocupacionais. Os programas de capacitação dos funcionários e trabalhos educativos desenvolvidos com a comunidade são destacados chamando os públicos à corresponsabilidade.

\footnotetext{
${ }_{17}$ Disponível em: <http://www3.braskem.com.br/upload/rao/2010/pt/glossario.html>. Acesso em: 08/06/2012.

${ }_{18}$ Disponível em: <http://www.braskem.com.br/site.aspx/produtos-verdes>. Acesso em: 08/06/2012.

${ }^{19}$ Disponível em: <http://www.braskem.com.br/site.aspx/manifesto-braskem-mudancas-climaticas>. Acesso em: 08/06/2012.

${ }^{20}$ Disponível em: <http://www.braskem.com.br/site.aspx/manifesto-braskem-mudancas-climaticas>. Acesso em: 08/06/2012.

${ }^{21}$ Relatório de Sustentabilidade de 2010. Disponível em: <http://www3.braskem.com.br/ upload/rao/2010/pt/pdf/Braskem

-RAS2010-Completo.pdf>. Acesso em: 07/06/2012.
} 


\section{CONSIDERAÇÕES FINAIS}

A análise demonstra que a composição do discurso das organizações escolhidas apresenta traços das três ideias-força apontadas, combinadas, em cada caso, segundo o tipo de negócio e conforme elementos macrodiscursivos que elas elegem como centrais para conferir o sentido de sustentabilidade. Observa-se, entretanto, uma ênfase particular na segunda vertente - a das práticas corretas. Enquanto a primeira ideia-força opera com elementos retóricos sobre a responsabilidade e a terceira se mostra de algum modo dependente do tipo de relação que as empresas estabelecem com os públicos e de como podem apresentar a eles as suas próprias atitudes, a segunda é a que de fato tende a materializar diretamente o seu conceito de sustentabilidade, comprovável pelas práticas produtivas, com forte apelo à tecnologia. Assim, as três vertentes se complementam de forma a produzir um campo de sentido coerente com a visão de sustentabilidade como valor e como narrativa civilizatória.

De modo mais geral, à medida que atribuem a si - e a tudo o mais relacionado a elas - o termo "sustentável", as organizações tendem primariamente a associar a ideia de sustentabilidade ao próprio negócio. Para enquadrar-se nessa espécie de metalinguagem da sustentabilidade, elas afirmam contribuir para a sobrevivência do planeta, sobretudo por meio do que fornecem. O foco fica nos produtos, apresentados como solução, e na otimização de processos produtivos, correlacionando diretamente a sustentabilidade à gestão organizacional. Como um efeito bumerangue, as ações sustentáveis tendem a ser aquelas capazes de impactar em produtividade e mais vendas. Posicionada como agente promotor da sustentabilidade, a existência da empresa é discursivamente construída como fator de interesse socioambiental. Esse enquadramento busca legitimar seu papel ativo, frequentemente vinculado a uma posição de centralidade em relação à definição de práticas sustentáveis. A construção discursiva aponta para um sentido geral de que ela não apenas é, em si mesma, sustentável, mas também um polo irradiador de sustentabilidade, uma promotora da ideia e das práticas sustentáveis para as demais esferas sociais.

\section{REFERÊNCIAS}

BRAGA, José Luiz. A sociedade enfrenta sua mídia: dispositivos sociais de crítica midiática. São Paulo: Paulus, 2006.

BROWN, Lester P. Plano B 4.0: mobilização para salvar a civilização. São Paulo: New Content / Ideia Sustentável, 2009.

FAIRCLOUGH, Norman. Discurso e mudança social. Brasília. Editora da Universidade de Brasília, 2001.

Recebido em: 03.09.2012 / Aceito em: 18.10.2012

${ }^{22}$ Disponível em: <http://www.braskem.com.br/site.aspx/visao-2020>. Acesso em: 07/06/2012. 